\title{
Rapid occurrence of sugar tricyclic orthoesters by acid catalyzed intramolecular orthotransesterification
}

\author{
Oscar M. Moradei ${ }^{a}$, Cecile du Mortier ${ }^{b^{*}}$, and Alicia Fernández Cirelli ${ }^{b}$ \\ ${ }^{a}$ MethylGene Inc. 7220 Frederick-Banting, Montreal, Quebec H4S 2A1, Canada \\ ${ }^{\mathrm{b}}$ Centro deEstudios Transdisciplinarios del Agua (CETA) and Área de Química Orgánica, \\ Facultad de Ciencias Veterinarias, Universidad de Buenos Aires, Av. Chorroarín 280, \\ C1427CWO Buenos Aires, Argentina \\ E-mail: cdm@fvet.uba.ar
}

Dedicated to Professor Dr. Rosa M. De Lederkremer on her $70^{\text {th }}$ anniversary

\begin{abstract}
The preparation of 6-O-(tert-butyldiphenylsilyl)- $\alpha$-D-glucopyranose 1,2,4-orthoacetate from 1,2$O$-(1-exo-methoxyethylidene)- $\alpha$-D-glucopyranose by acid catalyzed intramolecular orthotransesterification is described. A mechanism for the reaction is proposed.
\end{abstract}

Keywords: $\alpha$-D-Glucopyranose 1,2,4-orthoacetate, intramolecular orthoesterification, tricyclic orthoesters

\section{Introduction}

Tricyclic orthoesters of sugars are useful derivatives that allow regioselective modifications of the remaining free hydroxyl groups, such as tritylation of secondary HO at C-3 of $\alpha$-Dxylopyranose and $\beta$-L-arabinofuranose. ${ }^{1}$ Not only these rigid structures were used for conformational studies of pyranoses, ${ }^{2,3}$ but also proved to be of utility for the synthesis of the carbohydrate moiety present in bleomycin group antibiotics ${ }^{4}$ and for the preparation of novel materials as well. In this regards, Nakatsubo reported the first synthesis of modified cellulose by cationic ring-opening polymerization of 3,6-di-O-benzyl- $\alpha$-D-glucopyranose 1,2,4orthopivalate, ${ }^{5}$ with high stereoselectivity for the formation of $(1 \rightarrow 4)$ - $\beta$-glucosidic linkages and in high yield; ${ }^{6}$ therefore derivatives of $\alpha$-D-glucopyranose $1,2,4$-orthoesters can be considered valuable building blocks for the design of advanced materials from cellulose. ${ }^{7}$ Described herein is the preparation of $\alpha$-D-glucopyranose 1,2,4-orthoacetates, of potential utility as synthetic intermediates for highly functionalized cellulose. 


\section{Results and Discussion}

A synthetic route to thromboxane B2 required the preparation of D-glucopyranose derivatives suitably protected at hydroxyl groups at C-1, C-2 and C-6 for subsequent transformations at HO3 and -4 . One strategy involved the simultaneous esterification of HO-1 and -2 with an orthoacetate followed by regioselective protection at the primary HO-6. For this purpose, compound 2 was prepared as described in literature ${ }^{8,9}$ (scheme 1). In an initial protection attempt, orthoacetate 2 was treated with trityl chloride $\left(\mathrm{Ph}_{3} \mathrm{CCl}\right)$ in dry pyridine. However; instead the expected derivative, an amorphous solid was isolated. This compound was not characterized but its sepectroscopic features suggested a polymeric sugar derivative (probably a tritylated $\beta$ glucopyranan). Like their tricyclic analogues, bicyclic orthoesters are glycosylating agents that can be polymerized to give polysaccharides bearing 1,2-trans-glycosidic bond and an ester at HO-2. ${ }^{10,11}$

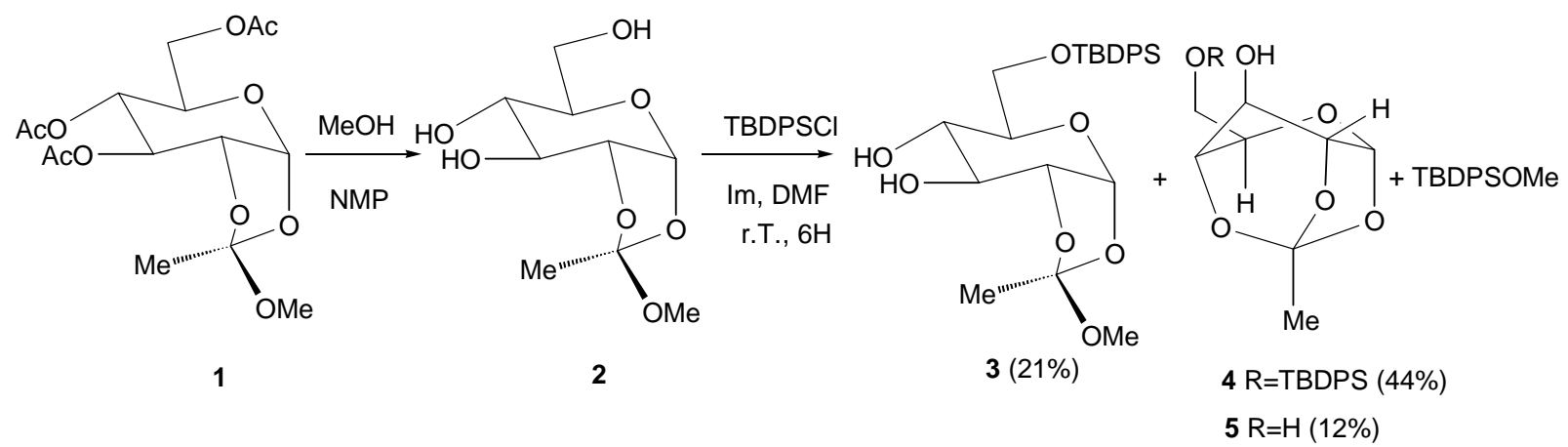

\section{Scheme 1}

A suitable protecting reagent should have reacted fast enough with 2 to prevent undesired acid catalyzed oligomerization; thus, tert-butyldiphenylsilyl chloride (TBDPSCl) was chosen. When tried on alcohol 2, expected derivative 3 was isolated in only $21 \%$ yield, being the main product silylated tricyclic orthoester 4 (44\% yield). Its ${ }^{1} \mathrm{H}-\mathrm{NMR}$ spectrum showed no signal at $3.22 \mathrm{ppm}$ corresponding to exo $\mathrm{OCH}_{3}$ group attached to ethylidene moiety but a singlet at 1.58 ppm characteristic of an orthoacetate $\mathrm{CH}_{3}$ group. Additional evidence of orthoester structure was provided by resonances at $119.3 \mathrm{ppm}$ and $20.8 \mathrm{ppm}$ for ethylidene $\mathrm{C}-\alpha$ and $\mathrm{C}-\beta$ respectively in ${ }^{13} \mathrm{C}$ NMR. Also, this spectrum showed no signal for exo $\mathrm{OCH}_{3}$ group at $50 \mathrm{ppm}$ and the $\mathrm{C}-4$ signal was shifted $4.4 \mathrm{ppm}$ upfield relative to the same signal in product $\mathbf{3}$, suggesting that intramolecular orthotransesterification occurred through the displacement of $\mathrm{CH}_{3} \mathrm{OH}$ by OH-4.

Two remaining products were also isolated: desilylated tricyclic orthoester 5 ( $12 \%$ yield), whose ${ }^{13} \mathrm{C}$ NMR resonances were almost identical to that of compound $\mathbf{4}$ except the signal of $\mathrm{C}$ 6, which was shifted $2.5 \mathrm{ppm}$ upfield due to the lack of TBDPS group; and TBDPS methyl ether, due to the reaction of the methanol released during orthotransesterification and the protective reagent. The early formation of TBDPS methyl ether explains not only the moderate yield for 
silylated species (65\% for 3 and 4 together) due to consumption of TBDPSCl by released methanol, but also is indicative that orthotransesterification was indeed very fast, and took place before all primary HO groups reacted. If this is the case, the formation of the polymeric sugar derivative during tritylation must have happened via oligomerization of compound 5 or its 6-Otrityl derivative. In fact, it has been reported that tritylation of 1,2-O-(1-exo-ethoxyethylidene)- $\alpha$ D-glucopyranose provided a low yield of 6-O-trityl- $\alpha$-D-glucopyranose 1,2,4-orthoacetate in addition to the expected product. ${ }^{12}$

The proposed reaction mechanism for intramolecular orthotransesterification is shown in scheme 2. The catalytic role of imidazole hydrochloride $(\mathrm{Im} . \mathrm{HCl})$ was demonstrated when a solution of compound $\mathbf{2}$ in dry DMF was treated with anhydrous Im. $\mathrm{HCl}$ : after one hour stirring at room temperature the reaction mixture showed two spots by tlc on silicagel with identical Rf of authentic samples of compounds $\mathbf{5}$ and $\mathbf{2}$ respectively.

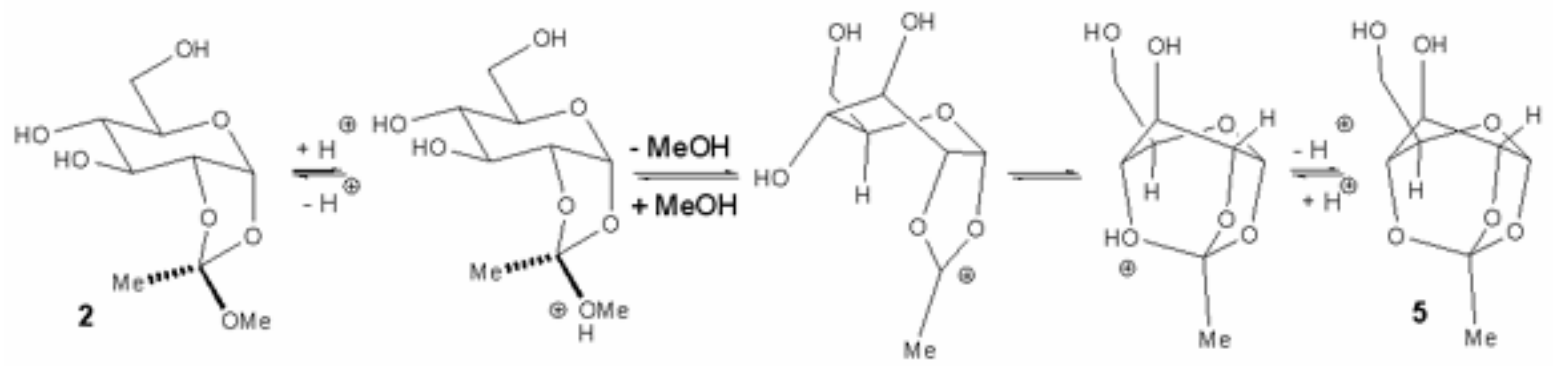

\section{Scheme 2}

A conformational search for compound 5 by computational modeling using Spartan '04 package $^{13}$ was set up by MMFF molecular mechanics force field in vacuum to localize all local minimum energy conformers, and then the relative conformer energies were determined using single-point 6-31G* Hartree-Fock calculations based on AM1 equilibrium geometries; the alignment of all seventeen conformers found is shown in figure 1, that clearly indicates the rigid conformation of the pyranosic ring, locked in a skew ${ }^{3} \mathrm{~T}_{2}$ conformation almost not perturbed among the conformers, in agreement with the conformation found for derivatives of $\alpha$-Dxylopyranose 1,2,4-orthoesters based on NMR studies. ${ }^{3}$ Moreover, the values of ${ }^{1} \mathrm{H}-{ }^{1} \mathrm{H}$ spin coupling constants obtained for compound 5 closely compare with those reported for 3-Oderivatives of $\alpha$-D-xylopyranose 1,2,4-orthoacetates or orthobenzoates ${ }^{3}$ (Figure 2, table 1) providing experimental support for the theoretical model. 


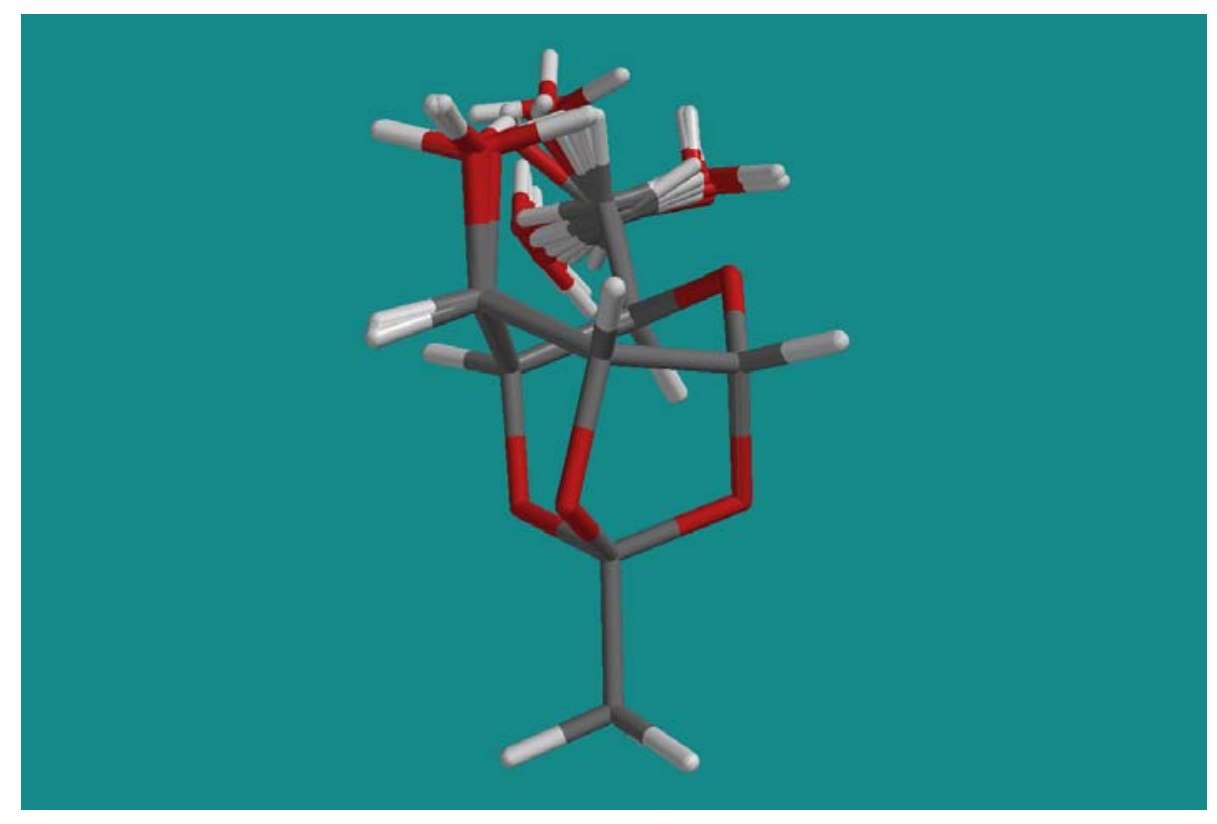

Figure 1. Alignment of seventeen conformers of compound 5.

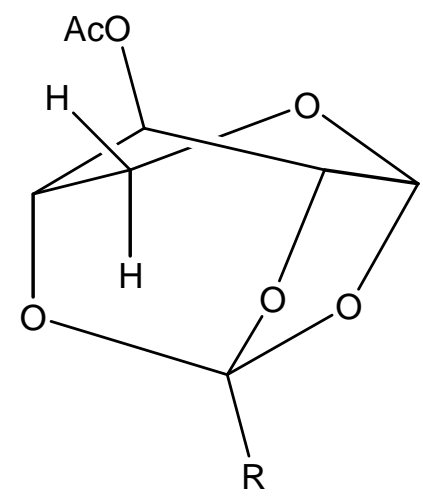

Orthoacetate: $\mathrm{R}=\mathrm{CH}_{3}$ Orthobenzoate: $\mathrm{R}=\mathrm{Ph}$

Figure 2. Structure of 1,2,4-orthoesters of $\alpha$-D-xylopyranose.

Table 1. Coupling constants for $\alpha$-D-xylopyranose 1,2,4-orthoesters ${ }^{\mathrm{a}}$

\begin{tabular}{cccccc}
\hline${ }^{1} \mathrm{H}^{1}{ }^{1} \mathrm{H}$ coupling constants & ${ }^{3} J_{1,2}$ & ${ }^{3} J_{2,3}$ & ${ }^{3} J_{3,4}$ & ${ }^{3} J_{4,5}$ & ${ }^{3} J_{2,4}$ \\
\hline$\alpha$-D-xylopyranose 1,2,4-orthoesters ${ }^{\mathrm{a}}$ & $4.5-4.8$ & $2.0-2.4$ & $4.4-4.5$ & $0.5-1.0$ & $2.0-2.4$ \\
Compound 5 & 4.5 & 2.2 & 4.5 & 0 & 2.0 \\
\hline
\end{tabular}

${ }^{\text {a }}$ Average values

Tricyclic orthoesters are valuable intermediates in the synthesis of higly functionalyzed cellulose derivatives and can be easily obtained by intramolecular orthotransesterification. 


\section{Experimental Section}

General Procedures. 100.1 MHz ${ }^{1} \mathrm{H}$ and $25.2 \mathrm{MHz}{ }^{13} \mathrm{C}$ NMR spectra were measured on a Varian XL-100 spectrometer. Chemical shifts $(\delta)$ are given in ppm downfield from tetramethyl silane in acetone- $d 6$ (otherwise indicated); coupling constants $(J)$ are given in Hz. Elemental analyses were carried out in the UMYMFOR service, FCEN, UBA. Optical rotations were measured at room temperature on a Perkin-Elmer 141 polarimeter, in methanol solution. 3,4,6tri-O-Acetyl-1,2-O-(1-exo-methoxyethylidene)- $\alpha$-D-glucopyranose (1) was prepared from tetraO-acetyl- $\alpha$-D-glucopyranosyl bromide by reaction with methanol in nitromethane using 2,6lutidine as proton scavenger, as described by Kochetkov. ${ }^{8}$ 1,2-O-(1-exo-methoxyethylidene)- $\alpha$ D-glucopyranose (2) was obtained by deacetylation of compound $\mathbf{1}$ under neutral, anhydrous conditions following a mild procedure developed in our laboratories. ${ }^{9}$

Procedure for the reaction of 1,2-O-(1-exo-methoxyethylidene)- $\alpha$-D-glucopyranose (2) with tert-butyldiphenylsilyl chloride. A solution containing $2(361 \mathrm{mg}, 1.5 \mathrm{mmol})$ and imidazole (248 mg, $3.6 \mathrm{mmol})$ in dry DMF $(5 \mathrm{~mL})$ was treated with tert-butyldiphenylsilyl chloride $(0.44$ $\mathrm{mL}, 1.7 \mathrm{mmol}, 1.1$ eq.). After stirring at room temperature for $6 \mathrm{~h}$, the solution was diluted with ethyl acetate, treated with Bio-Rex 70 ionic interchange resin (sodium form), filtered and concentrated under vacuo. Chromatographic separation on a silica gel column eluted with $25 \%$ to $100 \%$ ethyl acetate in hexane gave compound $4(301 \mathrm{mg}, 0.68 \mathrm{mmol}, 44 \%)$ along with 6-O-(tertbutyldiphenylsilyl)-1,2-O-(1-exo-methoxyethylidene)- $\alpha$-D-glucopyranose $\quad(3,154 \quad \mathrm{mg}, \quad 0.32$ mmol, 21\%) and $\alpha$-D-glucopyranose 1,2,4-orthoacetate $(5,38 \mathrm{mg}, 0.19 \mathrm{mmol}, 12 \%)$ in that order of elution. The most mobile component was eluted very early and characterized as $\mathrm{TBDPSOCH}_{3} .{ }^{1} \mathrm{H} \mathrm{NMR}, \delta$ (ppm, $\mathrm{CDCl}_{3}$ ): 7.88-7.32 (m, 10H, $\mathrm{H}_{\text {phenyl }}$ ); 3.54 (s, 3H, $\left.\mathrm{OCH}_{3}\right), 1.04$ (s, 9H, tert-butyl).

6-O-(tert-Butyldiphenylsilyl)- $\alpha$-D-glucopyranose $\mathbf{1 , 2 , 4 - o r t h o a c e t a t e ~ ( 4 ) . ~}[\alpha]_{\mathrm{D}}+23.6$ (c 1.10); ${ }^{1} \mathrm{H}$ NMR, $\delta(\mathrm{ppm}): 7.90-7.34$ (m, 10H, $\mathrm{H}_{\text {phenyl }}$ ); 5.79 (d, 1H, $\left.J_{1,2}=5.0, \mathrm{H}-1\right), 5.50$ (s, 1H, H-3), 4.50 (dd, $\left.1 \mathrm{H},{ }^{4} J_{2,4}=1.5, \mathrm{H}-2\right), 4.41$ (bs, $\left.1 \mathrm{H}, \mathrm{HO}\right), 4.37$ (dd, $\left.1 \mathrm{H}, J_{4,5}=2.5, \mathrm{H}-4\right), 4.24-4.11(\mathrm{~m}, 1 \mathrm{H}$, H-5), $4.00\left(\mathrm{dd}, 1 \mathrm{H}, J_{5,6}=5.0, J_{6,6}=10.0, \mathrm{H}-6\right.$ '), $3.96\left(\mathrm{dd}, 1 \mathrm{H}, J_{5,6}=4.0, \mathrm{H}-6\right), 1.58\left(\mathrm{~s}, 3 \mathrm{H}, \mathrm{CH}_{3}\right.$ ethylidene), 1.07 (s, 9H, tert-butyl). ${ }^{13} \mathrm{C} \mathrm{NMR,} \delta$ (ppm): 136.2-128.6 ( $\left.\mathrm{C}_{\text {phenyl }}\right), 119.2(\mathrm{C} \alpha$ ethylidene), 98.8 (C1), 78.6, 75.3, 74.0, 65.3, 65.1, $27.3\left(\mathrm{CH}_{3} \mathrm{C}\right), 20.8$ (C $\beta$ ethylidene), 19.7 $\left(\mathrm{CH}_{3} \mathrm{C}\right)$. Anal. Calcd for $\mathrm{C}_{24} \mathrm{H}_{30} \mathrm{O}_{6} \mathrm{Si}: \mathrm{C}, 65.13 ; \mathrm{H}, 6.83$. Found: $\mathrm{C}, 65.61, \mathrm{H}, 6.80$.

6-O-(tert-Butyldiphenylsilyl)-1,2-O-(1-exo-methoxyethylidene)- $\alpha$-D-glucopyranose (3). $[\alpha]_{\mathrm{D}}$ +13.7 (c 0.84); ${ }^{1} \mathrm{H}$ NMR, $\delta$ (ppm): 7.86-7.28 (m, 10H, $\left.\mathrm{H}_{\text {phenyl }}\right) ; 5.81$ (d, $\left.1 \mathrm{H}, J_{1,2}=5.0, \mathrm{H}-1\right), 4.27$ $\left(\mathrm{dt}, 1 \mathrm{H}, J_{2,3}=5.0, J_{2,4}=1.0, \mathrm{H}-2\right), 3.85\left(\mathrm{ddd}, 1 \mathrm{H}, J_{3,4}=2.0, J_{4,5}=6.0, \mathrm{H}-4\right), 3.72(\mathrm{~m}, 1 \mathrm{H}, \mathrm{H}-3)$, $3.71(\mathrm{~m}, 1 \mathrm{H}, \mathrm{H}-5), 3.44\left(\mathrm{dd}, 1 \mathrm{H}, J_{5,6}=3.0, J_{6,6}=11.0, \mathrm{H}-6\right.$ '), 3.33 (dd, $\left.1 \mathrm{H}, J_{5,6}=3.0, \mathrm{H}-6\right), 3.22$ (s, 3H, $\mathrm{OCH}_{3}$ exo), 1.61 (s, 3H, $\mathrm{CH}_{3}$ ethylidene), 1.06 (s, 9H, tert-butyl). ${ }^{13} \mathrm{C} \mathrm{NMR,} \delta(\mathrm{ppm})$ : 135.4-127.2 ( $\left.\mathrm{C}_{\text {phenyl }}\right), 122.1$ (Ca ethylidene), $98.7(\mathrm{C} 1), 80.1,75.1,75.0,69.7,65.0,49.9\left(\mathrm{OCH}_{3}\right)$, $27.3\left(\mathrm{CH}_{3} \mathrm{C}\right), 23.6(\mathrm{C} \beta$ ethylidene $), 19.9\left(\mathrm{CH}_{3} \mathrm{C}\right)$. 
a-D-Glucopyranose 1,2,4-orthoacetate (5). $[\alpha]_{\mathrm{D}}+49.1$ (с 0.39); ${ }^{1} \mathrm{H} \mathrm{NMR}, \delta$ (ppm): 5.78 (d, 1H, $\left.J_{1,2}=4.5, \mathrm{H}-1\right), 5.16\left(\mathrm{ddd}, 1 \mathrm{H}, J_{2,3}=2.2,{ }^{4} J_{2,4}=2.0, \mathrm{H}-2\right), 4.53(\mathrm{~m}, 1 \mathrm{H}, \mathrm{H}-3), 4.37$ (dd, $1 \mathrm{H}, J_{5,6}=$ $4.5, J_{6,6}=10.5$, H-6'), 4.35 (dd, $1 \mathrm{H}, J_{5,6}=4.5$, H-6), 4.28 (t, $\left.1 \mathrm{H}, \mathrm{H}-5\right), 4.06$ (dd, $1 \mathrm{H}, J_{3,4}=4.5$, H4), 3.87 (bs, 2H, HO), 1.54 (s, 3H, $\mathrm{CH}_{3}$ ethylidene). ${ }^{13} \mathrm{C} \mathrm{NMR,} \delta$ (ppm): 120.6 (Ca ethylidene), 98.7 (C1), 78.6, 75.3, 75.0, 65.0, 62.6, 20.7 (C $\beta$ ethylidene).

\section{Acknowledgements}

The authors are indebted to Universidad de Buenos Aires and Consejo Nacional de Investigaciones Científicas y Técnicas (CONICET) for financial support.

\section{References}

1. Wozney, Y. V.; Kochetkov, N. K. Carbohydr. Res. 1977, 54, 300.

2. Vorontsova, L. G.; Bochkov, A. F.; Obruchnikov, I. V.; Andrianov, V. I.; Tarnopolsky, B. L. Carbohydr. Res. 1972, 23, 326;

3. Bochkov, A. F.; Dashunin, V. M.; Kessenikim, A. V.; Kochetkov, N. K.; Naumov, A. D.; Obruchnikov, I.V. Carbohydr. Res. 1971, 16, 497,

4. Millar, A.; Hyup Kim, K.; Minster, D. K.; Ohgi, T.; Hecht, S. M. J. Org. Chem. 1986, 51, 189

5. Karakawa, M.; Nakatsubo, F. Carbohydr. Res. 2002, 337, 951

6. Nakatsubo, F.; Kamitakahara, H.; Hori, M. J. Am. Chem. Soc. 1996, 118, 1677

7. Heinze, Th.; Koschella, A. Macromolecular Symposia 2005, 233, 13

8. Kochetkov, N. K.; Khorlin, A. J.; Bochkov, A. F. Tetrahedron 1967, 23, 693

9. Moradei, O.; Leit, S; du Mortier, C.; Fernández Cirelli, A.; Thiem, J. J. Carbohydr. Chem. 1993, 12,13

10. Kochetkov, N. K.; Yazlovetsky, I. G.; Bochkov, A. F. Carbohydr. Res. 1969, 9, 49;

11. Kochetkov, N. K.; Bochkov, A. F. Carbohydr. Res. 1969, 9, 61

12. Bochkov, A. F.; Zaikov, G. E. Chemistry of the O-Glycosidic Bond: Formation and Cleavage; Pergamon Press: Oxford, 1979.

13. Wavefunction Inc. Irvine, CA 92612, 2004. 